\title{
Modification of the optimization model for simulation of large-diameter pipes bending
}

\author{
Marián Handrik ${ }^{1,}$, Filip Dorčiak ${ }^{1}$, Milan Sága ${ }^{1}$, Milan Vaško $^{1}$, Lenka Jakubovičová ${ }^{1}$ \\ ${ }^{1}$ University of Žilina, Faculty of Mechanical Engineering, Department of Applied Mechanics, \\ Univerzitná 8215/1, 01026 Žilina, Slovak Republic
}

\begin{abstract}
This paper presents a modification of the existing optimalization model in order to increase the accuracy of the solution in the initial and the end part of the bend. Developed optimalization algorithms are implemented in the program MATLAB, and the simulation of the bending process is solved in the FEM program ADINA. Created optimisation program automatically generate model for FEM analysis and automaticaly analyses obtained results from FEM analysis.
\end{abstract}

Keywords: Finite element method, pipe bending, pipe tickness, induction heating, splay cooling

\section{Introduction}

The created optimization model for determining the shape of a blank for bending largediameter tubes with induction heating is showing several insufficiencies [1]. The proposed changes aim to improve the behavior of the calculation model and to increase the accuracy of the resulting shape of the tube after bending. Bending of large diameter tubes with induction heating changes the thickness of the wall of the pipe. The thickness of the pipe wall increases on the inside of the bend and the thickness of the pipe wall decreases on the outside of the bend. The blank is machined from the outside, so that after bending, the thickness of the pipe wall is the same at all locations. The technological process of the pipe bending with the induction heating is shown in Fig. 1.

\section{Modification of optimization model}

The old optimization model divides the geometry of the bent pipe into three parts. The new optimization model has the geometry divided into three parts, dividing geometry into three parts is addequatly and accurate:

- Initial bend zone. In this zone, the plastic deformation of the pipe is not yet fully realized as in the middle part of the pipe. The old model optimizes the thickness of the pipe wall in three places: at the beginning, centre and end of this zone. The new model optimizes the wall thickness of the pipe in five places with the same spacing.

\footnotetext{
* Corresponding author: marian.handrik@fstroj.uniza.sk

Reviewers: Marian Dudziak, Kateryna Kravchenko
} 
- Ending bend zone. There are the same changes at the ending zone as at the initial bend zone. There was created the same changes. In the end bend zone, as at the initial bend zone, the number of places for optimizing the wall thickness is increased from three to five.

- Middle bend zone. Geometry model for this zone is the same for old and new model. The optimization of the wall thickness is counted for three places in this middle zone.

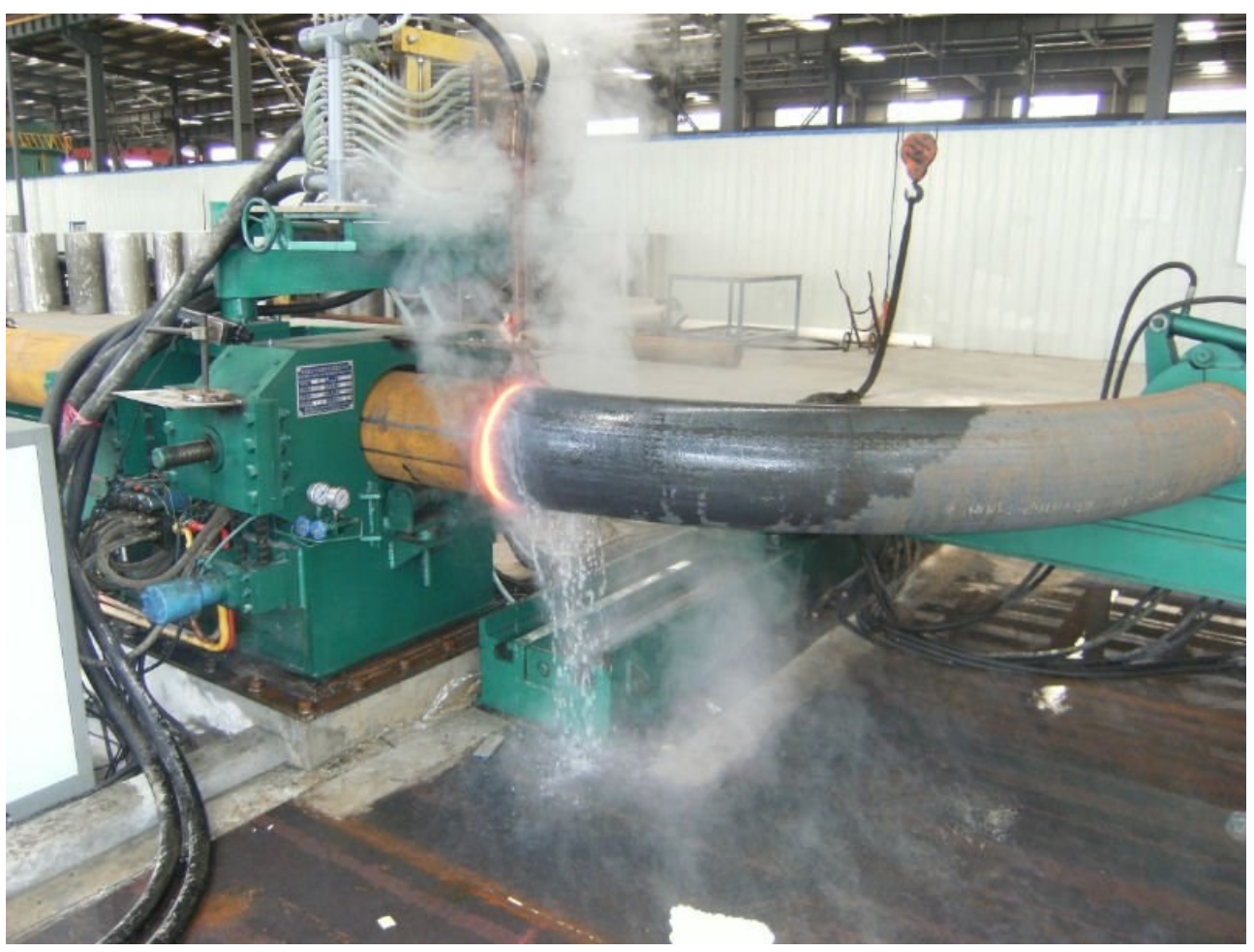

Fig. 1. Bending pipe with induction heating and spray cooling

The computational model contains optimization parameters for the length, that change the position of the individual optimization zones, further parameters change the thickness of the pipe wall in these zones. When the all optimization parameters are used in the same time, the optimization task is not convergent. The solution is to divide the optimization parameters into three groups and to use the method of the cyclical change of the optimization parameters. We create three sets of parameters:

- The first set of parameters. Optimization of the outer dimensions and position of the area of plastic deformation on the pipe. The parameters of this group determine the position of the beginning of the plastic deformation, the position of the end of the plastic deformation, and the total displacement coefficient of the pipe at bending. The actual displacement is larger than the theoretically calculated displacement to achieve the prescribed bending angle of the pipe. The plasticization of the pipe bending is shortened.

- The second set of parameters. This parameters are used for optimization of the length of the initial and ending plastization zones. They determine the interface between the initial and central plasticization zones similar to the central and ending plastization zone.

- The third set of parameters. This parameters are used for the optimization of the wall thickness of the pipe in seven vectors of the wall thickness of the pipe. The thickness of the pipe wall is defined at 19 points halfway through the pipe circumference. In this group of optimization parameters, optimization of the overall displacement of the pipe is also 
redefined - when changing the thickness of the pipe wall, the size of the pipe pressure is changed.

In both the old and the new computation model, the second and third set of parameters are changed.

When optimizing the first and second parameter sets, the modified Golden Cut method is used. The modified Full Stress Design method is used to optimize the wall thicknesses of the pipe. The new geometric model used in the modified optimization model is shown in Fig. 2.

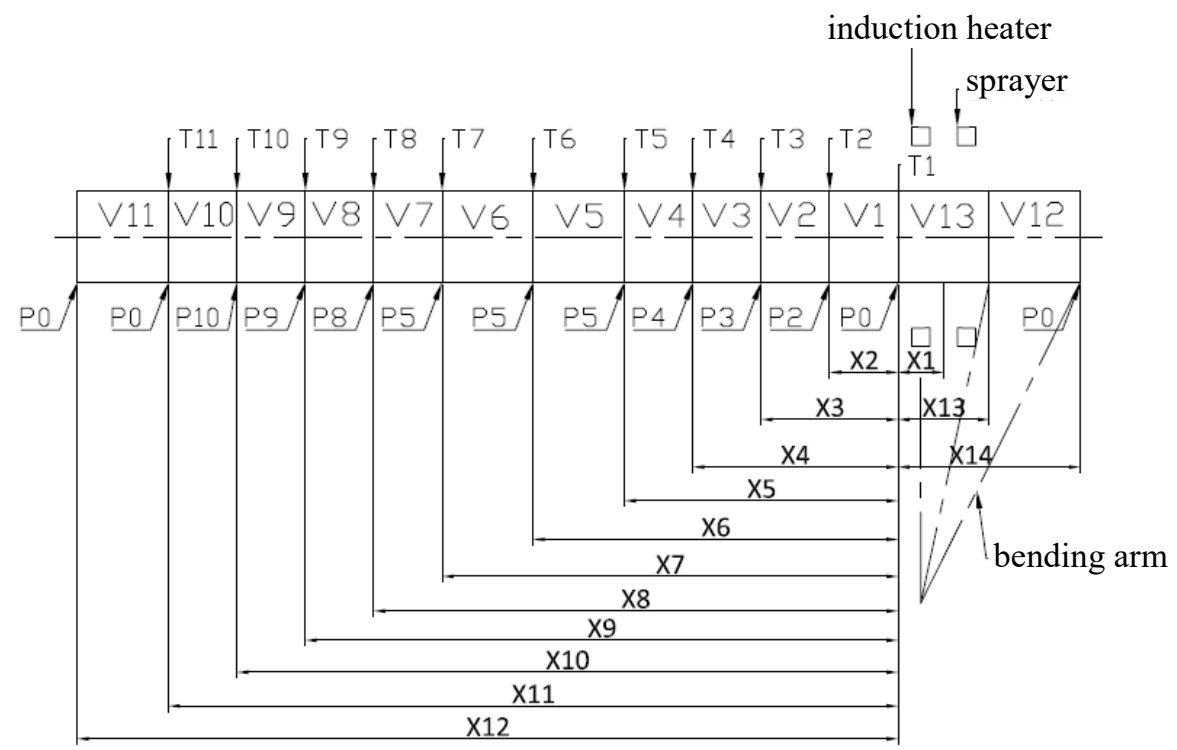

Fig. 2. Geometry model for optimization model

\section{Finite element model}

Half of the pipe geometry is created, model symmetry is used in the FEM model. The symmetry condition is defined in the plane of symmetry. The bending arm is meshed by truss elements. All degrees of freedom are removed, at the end of the bending arm. The combination of truss elements and the removal of all degrees of freedom at the end of the rods allows rotation around this point. A displacement is prescribed in the direction of the pipe axis, all other degrees of freedom are removed, at the free end of the pipe This displacement causes the pipe bending [2-7].

The bilinear thermal depend material model is used in both the old and the new model. The linear elastic material model is used for other parts of the model.

Induction heating and cooling sprayer are modeled using contact with heat transfer [8-10]. A set of bodies with one element is created, in the place of the inductor and the sprayer. These elements have the heating temperature $950^{\circ} \mathrm{C}$ and the temperature of the cooling water is $20^{\circ} \mathrm{C}$. Replacing induction heating and water sprayer by the contact with heat transfer sufficiently accurately models the heat flow in the pipe. Such replacement is very time-efficient and makes it possible to significantly increase the speed of the optimization model. 
The model of the pipe is designed as a volume model, and linear hexahedron elements are used to mapped meshing. Four elements are generated on the wall thickness of the pipes. The finite element model is shown in Fig. 3.

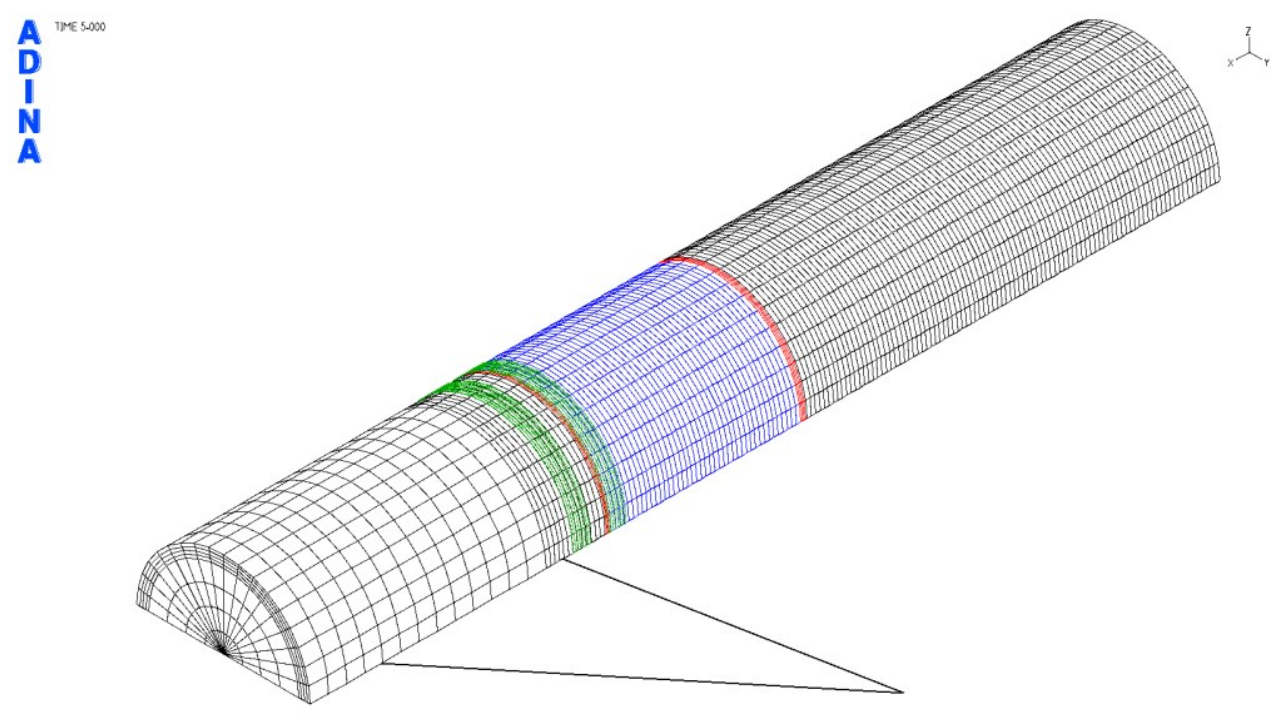

Fig. 3. Geometry model for optimization model

\section{Comparison of old and new model}

We compared the suitability of changes in the optimization model by comparing the calculation using both the old and the new optimization model. We performed a series of calculations for a 10 inch pipe diameter, $24 \mathrm{~mm}$ wall thickness and with the following bending radiuses of $1.5,1.6,1.7,1.8,1.9,2.0,2.1,2.2,2.3,2.4,2.5$. Comparison of models with respect to convergence of computational models is presented in Tab. 1 .

A comparison of the required number of cyclical changes of the optimization parameters as well as the number of iterations needed to convert a single cyclic parameter change is given in Tab. 2.

The resulting shape of pipe bend for the new optimization model is shown in Fig. 4 and for old optimization model in Fig. 5. 
Table 1. Convergence for old and new model

\begin{tabular}{|c|c|c|}
\hline Bending radius & Old model & New model \\
\hline 1.5 & Not converged & Not converged \\
\hline 1.6 & Not converged & Not converged \\
\hline 1.7 & Not converged & Converged \\
\hline 1.8 & Not converged & Not converged \\
\hline 1.9 & Converged & Not converged \\
\hline 2.0 & Converged & Converged \\
\hline 2.1 & Converged & Converged \\
\hline 2.2 & Converged & Converged \\
\hline 2.3 & Converged & Converged \\
\hline 2.4 & Converged & Converged \\
\hline 2.5 & Converged & Converged \\
\hline
\end{tabular}

Table 2. Number of iteration for convergence old and new model, bending radius 2.0-2.5

\begin{tabular}{|c|c|c|c|c|c|c|c|c|c|c|c|c|}
\hline \multirow{2}{*}{$\begin{array}{c}\text { Parameter } \\
\text { group }\end{array}$} & \multicolumn{10}{|c|}{ Bending radius } \\
\cline { 2 - 18 } & \multicolumn{2}{|c|}{2.0} & \multicolumn{2}{|c|}{2.1} & \multicolumn{2}{|c|}{2.2} & \multicolumn{2}{c|}{2.3} & \multicolumn{2}{|c|}{2.4} & \multicolumn{2}{|c|}{2.5} \\
\cline { 2 - 17 } & new & old & new & old & new & old & new & old & new & old & new & old \\
\hline 1. & 14 & 8 & 15 & 8 & 12 & 9 & 12 & 9 & 12 & 8 & 12 & 8 \\
\hline 2. & 15 & 3 & 14 & 3 & 15 & 3 & 13 & 3 & 14 & 3 & 14 & 3 \\
\hline 3. & 7 & 11 & 5 & 11 & 5 & 12 & 5 & 11 & 5 & 11 & 8 & 12 \\
\hline 1. & 10 & 9 & 12 & 9 & 11 & 9 & 11 & 9 & 10 & 9 & 10 & 9 \\
\hline 2. & 10 & 2 & 11 & 2 & 12 & 2 & 12 & 8 & 12 & 2 & 12 & 2 \\
\hline 3. & 3 & 8 & 2 & 8 & 3 & 9 & 3 & 10 & 3 & 9 & 3 & 8 \\
\hline 1. & - & 10 & - & 10 & - & 10 & - & 11 & 12 & - & 12 & 10 \\
\hline 2. & - & 2 & - & 2 & - & 1 & - & 1 & 11 & - & 11 & 1 \\
\hline 3. & - & 10 & - & 10 & - & 19 & - & 10 & 2 & - & 4 & 10 \\
\hline 1. & - & - & - & - & - & 2 & - & - & - & - & - & - \\
\hline 2. & - & - & - & - & - & 7 & - & - & - & - & - & - \\
\hline Total & 54 & 59 & 54 & 55 & 53 & 72 & 50 & 58 & 73 & 37 & 78 & 55 \\
\hline
\end{tabular}




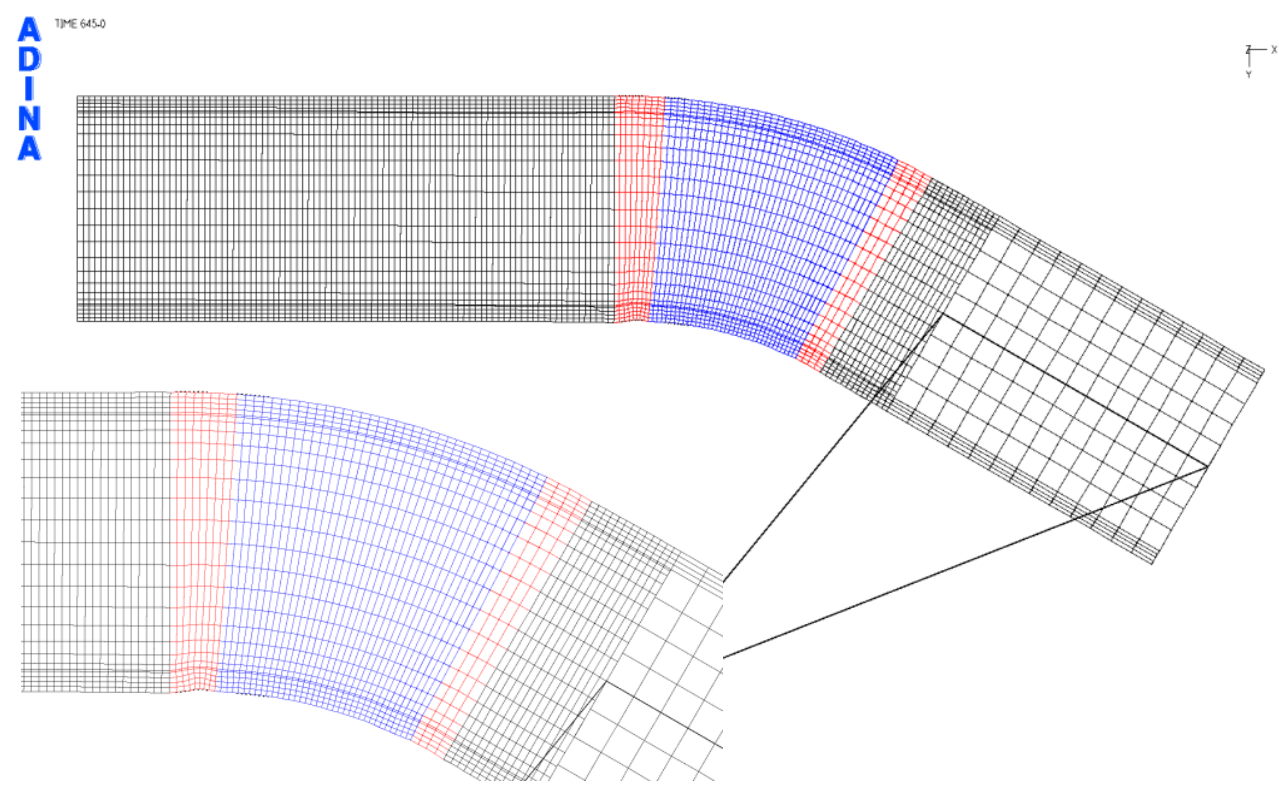

Fig. 4. New optimization model $\mathrm{R}=2.5$

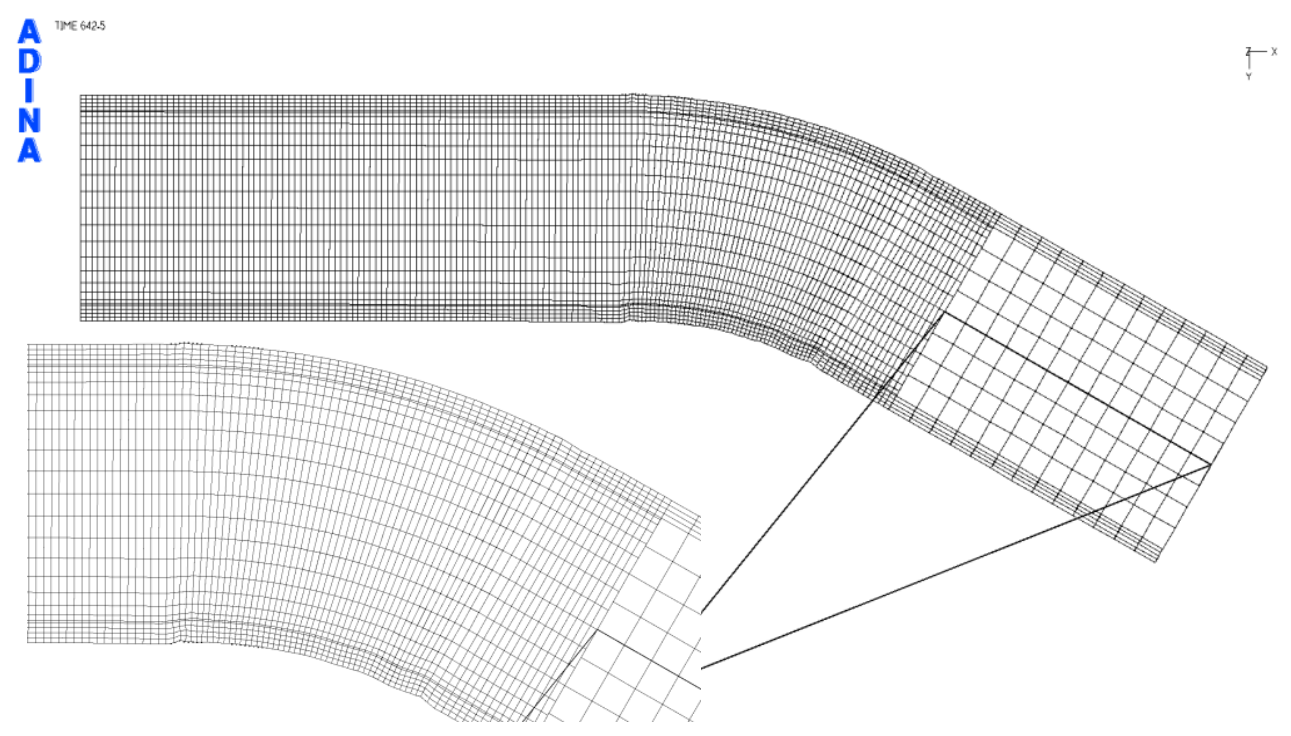

Fig. 5. Old optimization model $\mathrm{R}=2.5$

\section{Conclusion}

The new optimization model shows the following improvements:

- Improved shape in the initial plastic zone, reducing the corrugation on the internal bend radius. 
- Improved shape in the end plastic zone, reducing the corrugation on the internal bend radius.

- Reduction of the total number of necessary iterations.

Model changes were tested for one diameter and one pipe thickness. In practice, pipe bends are made with a large number of combinations of wall thicknesses and pipe diameters at different bending radii to the diameter of the pipe. In the following research, it is necessary to test a new calculation model for further combinations of pipe wall thicknesses and pipe diameters as well as to experimentally verify the obtained results and material structures of pipes [11-22].

The contribution was created on the basis of the financial support of the grant project APVV 14-0096 a KEGA 037ŽU-4/2018.

\section{References}

1. M. Sága, M. Handrik, P. Kopas, M. Tropp, Analysis of the influence of the pipe's wall thickness on the corrugation of the surface during inductive bending of pipes. MATEC Web of Conferences, 157, (2018)

2. R. Halama, P. Macura, L. Pecenka, F. Fojtik, M. Sofer, Experimental Analysis of Residual Stresses in Backup Roll and FE solution. Experimentalni analyza napeti experimental stress analysis, 85-90 (2011)

3. V. Dekys, P. Kopas, M. Sapieta, O. Stevka, A detection of deformation mechanisms using infrared thermography and acoustic emission. Novel Trends in production devices and systems, 474, 315-320 (2014)

4. R. Grega, J. Krajnak, L. Zulova, G. Fedorko, V. Molnar, Failure analysis of driveshaft of truck body caused by vibrations. Engineering Failure Analysis 79, 208-215 (2017)

5. M. Macko, J. Flizikowski, Z. Szczepanski, K. Tyszczuk, G. Smigielski, A. Mrozinski, J. Czerniak, A. Tomporowski, CAD/CAE Applications in Mill's Design and Investigation. Lecture Notes in Mechanical Engineering, 343-351, (2017)

6. G. Domek, M. Dudziak, A. Kolodziej, Timing belt gear design for mechatronics system. Procedia Engineering, 96, 39-43, (2014)

7. L. Jakubovicova, M. Saga, Computational analysis of contact stress distribution in the case of mutual stewing of roller bearing rings. Novel Trends in production devices and systems, 474, 363-368 (2014)

8. J. Vavro, J. Vavro Jr., P. Kovacikova, R. Bzdedova, The optimisation of the materials properties for the passenger cars in dependence on defect distribution at the dynamic loading. Procedia Engineering, 136, 114-119 (2016)

9. F. Klimenda, J. Soukup, Josef, J. Kampo, Heat Distribution in Disc Brake. AIP Conference Proceedings, 1745, (2017)

10. J. Zapomel, V. Dekys, P. Ferfecki, A. Sapietova, M. Saga, M. Zmindak, Identification of Material Damping of a Carbon Composite Bar and Study of Its Effect on Attenuation of Its Transient Lateral Vibrations. International Journal of applied mechanics, 7 (2015)

11. P. Orsansky, B. Ftorek, P. Durcansky, Mathematical model of a closed hot air engine cycle using MATLAB Simulink. AIP conference proceedings 1608, 173-176 (2014)

12. T. Domanski, W. Piekarska, M. Kubiak, Z. Saternus, Determination of the final microstructure during processing carbon steel hardening. Procedia Engineering, 136, 77-81 (2016) 
13. I. Kuric, V. Bulej, M. Saga, P. Pokorny, Development of simulation software for mobile robot path planning within multilayer map system based on metric and topological maps. International journal of advanced robotic systems, 14, (2017)

14. M. Bruna, D. Bolibruchova, R. Pastircak, Reoxidation processes prediction in gating system by numerical simulation for aluminium alloys. Archives of foundry engineering, 17, 23-26 (2017)

15. R. Halama, A. Markopoulos, F. Fojtik, M. Fusek, Z. Poruba a J. Famfulik, Effect of stress amplitude on uniaxial ratcheting of aluminum alloy. Materialwissenschaft und Werkstofftechnik, 48, 814-819 (2017)

16. V. P. Mateichyk, V. P. Volkov, P. B. Komov, I. V. Gritsuk, et al., Special features of vehicle condition monitoring using onboard diagnostics systems. Project management, systems analysis and logistics: Scientifc journal, K.: NTU, 13, 126-138, (2014)

17. Y. Turygin, P. Bozek, I. Abramov, Y. Nikitin, Reliability determination and diagnostics of a mechatronic system. Advances in science and technology-research journal, 12, 274-290, (2014)

18. E. Kalentev, S. Vaclav, P. Bozek, V. Tarasov, A. Korshunov, Numerical analysis of the stress-strain state of a rope strand with linear contact under tension and torsion loading conditions. Advances in science and technology-research journal, 11, 231-239, (2017)

19. P. Krawiec, G. Domek, Ł. Warguła, K. Waluś, J. Adamiec, The application of the optical system ATOS II for rapid prototyping methods of non-classical models of cogbelt pulleys. MATEC Web of Conferences, 157, (2018)

20. P. Krawiec, Numerical Analysis of Geometrical Characteristics of Machine Elements Obtained Through CMM Scanning. Progress in Industrial Mathematics at ECMI 2008, $15,933-938$ (2010)

21. T. Lack, J. Gerlici, a modified strip method to speed up the calculation of normal stress between wheel and rail. Experimental stress analysis 51, 486, 359-370, (2014)

22. J. Palieskova, M. Pajtasova, A. Feriancova, A. D. Ondrusova, K. Holcova, J. Vavro, J., Jr., S. C. Mojumdar, Thermal properties of fillers based on organoclays in the polymeric materials. Journal of thermal analysis and calorimetry, 199, 939-943, (2015) 